\section{TEXTBOOK OF OPERATIVE SURGERY}

By Eric L. Farquharson, M.D., F.R.C.S. Pp. viii +853 , with 623 illustrations. Edinburgh: E. \& S. Livingstone Ltd. 1954. 75 s.

Mr. Farquharson has written a new textbook of operative surgery, principally for the trainee in general surgery, and, while filling a long-needed requirement in this sphere, may also prove of interest to the experienced surgeon, particularly for reference to the less commonly performed operations. The volume is compact, yet covers nearly all the operative procedures which may be required of the general surgeon, and in addition many of the classical but rarely indicated operations are described.

In each section there is a precis of the surgical anatomy, and the indications for surgery, and principles of the operation are carefully described. The techniques are described in considerable detail, assisted by many excellent illustrations, photographs and several colour reproductions. The relevant references to the literature are included in the text. There are valuable chapters on the treatment of wounds and fractures, and a particularly useful section on the surgery of the hand which is a model of condensation of the relevant information on this wide and important field. Orthopaedic, thoracic and neurosurgical operations are dealt with, as also are the techniques for cystoscopy and sigmoidoscopy, but endoscopic examination of the oesophagus, bronchus, stomach and urethra are omitted. Notes on pre- and postoperative care are included where relevant. Criticisms are few, but insufficient emphasis is placed upon haemostasis in gastro-jejunal anastomosis, particularly where a Connell stitch is used, and restorative resection of the rectum would merit a more detailed description, particularly with regard to the blood supply of colon and the technique of anastomosis of the rectal stump.

The author's teaching is orthodox and his style concise and easy to follow. The volume is produced on good quality paper, soundly bound, and provided with a satisfactory index. This new textbook should be of particular value to the Fellowship candidate and has the essential qualities of a 'best seller' in this field.

J.R.K.

\section{LECTURES ON GENERAL PATHOLOGY}

Edited by Sir Howard Florey, M.D., F.R.C.P., F.R.S. Pp. xiii +733 , illustrated. London: Lloyd-Luke Ltd. I954. 63 s.

A course in general pathology and bacteriology lasting for two terms of eight weeks each given at the Sir William Dunn School of Pathology in the University of Oxford has provided the 'basis and the stimulus for this very welcome book. The 37 lectures cannot, of course, form a complete survey of general pathology, but deal with subjects which have engaged the interest of the ro authors for a long time.

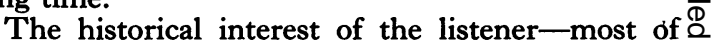
the lectures are written so vividly that the reader $c$. becomes a listener-is aroused by the first lecture $\overrightarrow{\vec{F}}$ and kept stimulated by numerous portraits bringing $\stackrel{\oplus}{+}$ to life the famous names in pathology. Inflammation, $\frac{}{c}$ degeneration, reaction of the blood to injury, fever, 을 the effects of radiation, antigen and antibodies, $\frac{\bar{s}}{\circ}$ pathogenicity and virulence of micro-organisms, $\mathbb{\otimes}$ immunity, anaphylaxis, hypersentivity, healing and regeneration, haemorrhage and shock, oedema, $\infty$ connective tissue function and tuberculosis are $\vec{\circ}$ dealt with in this order. The last two lectures give a concise review of antiseptic, antibiotic and anti- $\vec{\omega}$ bacterial substances.

Throughout there is the emphasis on the experi- $\vec{C}$ ment and the experimental basis of physiological 3 . and pathological observations. This must, if anything does, make the 'better type of student ' think $\vec{\omega}$ and give him a grounding which is invaluable for $\mathcal{H}_{\mathrm{H}}$ the introduction to what Sir Thomas Lewis called ${ }^{\mathcal{H}}$ clinical science. One would wish one had the time $\vec{A}$ to read this book at least once a year and one is left with the hope that another series of like lectures may be collected in the near future for the edification and indeed the delight of all students of pathology.

E.N.

\section{SEXUAL DISORDERS IN THE MALE}

By K. Walker, F.R.C.S., and E. B. Strauss, M.A., D.M., D.Sc., F.R.C.P. 4th Edition. ‡ Pp. xiii +260 , with eight illustrations. London: $\stackrel{\mathbb{Q}}{\mathscr{Q}}$ Cassell \& Co. Ltd. I954. I8s. 6d.

Comparing this work with its earlier editions, 윽 practitioners who have grown to regard this book as an old and valued friend need not fear that any gross mutation has altered its essential character. The authors state in their preface that the chapter on the surgical treatment of impotence, which they thought had become obsolete, has been eliminated, but the entire contents, with the exception of Lowsley's plication of the bulbo- and ischiocavernosus, now appear jointly with the medical methods of treatment. Few will quarrel with this 0 retention, for these surgical examples complete the picture and provide a deeper understanding of the impotent patient's needs. A chapter on the concepts 'male' and 'female' has been added, $N$ drawn mainly from Margaret Mead's well-known work among primitive cultures, and its importance 0 here is the light it throws on the environmental $\underset{\omega}{N}$ influences on socio-sexual behaviour. Only minor alterations and additions have been made to the rest of the book, which retains the high standard and readability of the earlier editions, and which deserves a place in every general practitioner's c nsulting room.

L.R.C.H: 